\title{
Internet Applications, Sites, Trends and Happenings
}

\author{
David Raitt \\ draitt@estec.esa.nl
}

This column aims to draw your attention to various interesting Web sites which I have come across and which might appeal to you, and to keep you up to date with news and views on Web trends and developments. It offers essentially a personal selection rather than comprehensive coverage.

\section{The size of the Web}

No-one really knows how huge the Web is. When Alta Vista first appeared in December 1995, it used an index much larger than the other search engines at the time - forcing the others to catch up. In June 1998, AltaVista was still ahead with some 140 million or so pages indexed; in September 1999 FAST was covering 200 million. By December AltaVista was back with 250 million, then in January 2000 FAST broke the 300 million barrier - soon after AltaVista did the same. By November the same year FAST was up to 575 million, WebTop was indexing 500 million, as was Inktomi, while AltaVista was lagging at only 350 million. In June 2000 the search engine Google announced that it had a full-text index to 560 million URLs (i.e. equivalent to pages), by November it was 602 million - but because of the way Google makes use of link data and thus returns listings for sites it has never actually visited, its reach was actually claimed to encompass a further 600 or so million URLs. Clearly this 1.2 billion pages on the Web will have increased over the last few months since then and, in any event, the estimate does not include the millions (possibly billions) of pages that search engines do not typically crawl, such as those that are password protected, residing behind query boxes or in non-indexable databases (http://searchenginewatch.com/reports/sizes.html).

Despite the relatively small size (now, compared to the others) of AltaVista, it has the most searches performed on it - some 50 million per day, compared to 47 million for Inktomi, 40 million for Google and only 12 million for FAST

(http://searchenginewatch.com/reports/perday.html).

\section{Privacy and the Web}

In the paper that I gave at the 2nd World-Wide Web Applications conference last year, I talked about the issues of privacy. A piece in the Daily Telegraph's Connected supplement (26 Oct 2000) (http://www.telegraph.com) talks about the death of privacy. Any dotcom worthy of its business plan monitors your surfing habits - logging your interests, measuring how long you spend on a page, recording which pages or banner advertisements you click on and collating any personal data which you may give into a profile. Such behaviour would not be tolerated in the real world, but it seems to be an acceptable part of today's Internet world. 
To be honest, much of it is unobtrusive and benign - collecting information in order to be more helpful to you - telling you about new books or music you might like to know about given your tastes, suggesting places you might like to visit based on previous trips you have made. And this is no different to the data collected by supermarkets, department stores, airlines and the like with their club and loyalty cards. It is when this data are sold to others that there is often a problem - the unsolicited e-mails and junk mail which will not go away.

In many countries (including the United States where 50\% of the Web hosts reside) there is no law against selling such data. In the UK, personal data are supposedly protected under the 1998 Data Protection Act and if you feel that your personal data have been misused, then you can do something about it. Moreover, it is an offence to transfer personal data to a third country. The USA has no such inhibitions or prohibitions. Some dotcoms have folded - and sold their mailing lists to raise some capital. Amazon recently announced a change in its privacy policy and said that in the event of a collapse, it might sell its lists - which include credit card details. Currently, UK customers are safe, but a new law recently came into force between the European Union and the USA which means that Amazon UK or Amazon Germany could transfer personal data to the parent company in the States without falling foul of European data protection laws.

Well, personal data about books probably are not too bad, but what if the data are about medical history or credit rating details? The Connected article also gives a more insidious view: Say you slipped and fell in the supermarket, hurt yourself and claimed compensation. The supermarket might be able to check the personal profile it had compiled on you and find that you regularly bought alcohol and thus possibly argue that you were an alcoholic and were drunk when you fell.

In my WWW paper, I also talked about office privacy - well, businesses in the UK now have the right to snoop into employee's e-mails and Web surfing habits. Once employees have been made aware that communications may be monitored, the company is entitled to read e-mails and check Web access for the purpose of catching unlawful, fraudulent or improper use of company equipment and communication systems.

A recent workplace privacy survey conducted by the Society for Human Resource Management in the United States found that 74\% of 722 companies monitored workers' Internet use at work. Seventy-two per cent said that they checked on employees' e-mail and $51 \%$ reviewed phone-calls

(http://www.cnn.com/2001/CAREER/trends/01/02/surveillence.index.html). Does this mean that companies generally distrust staff to behave in a responsible manner? Or have a few spoiled it for the many? Or is it everyone who is at it? The survey also found that some $40 \%$ of companies monitored communications for cause, but $30 \%$ or so monitored at random. The most common reason cited for the monitoring was to evaluate performance (yeah, right!) with quality control listed next. One fifth of people interviewed said they received at least one potentially offensive e-mail from a co-worker per month - another reason for monitoring.

Another survey found that one in three corporate workers said that they spent 25 minutes or longer each day at work using the Internet for personal business - shopping for instance.

Well, I don't know about that, but many people do use the office communication system connected to the Internet for sending personal notes to friends and family and for sending jokes, etc. Where is the harm in that provided it is in moderation?

Of course, as I also pointed out - this kind of snooping policy is at variance with other laws respecting human rights, so we shall have to see how it all pans out. The bottom line is, 
though, be careful of what personal information you give away on the Web or indeed in any survey - and also be careful how you use your computer at work!

And now to a different kind of privacy. ptClub offers tax free offshore services (e.g. bank accounts), immigration services, free and second passports, nobility titles, offshore maildrops, quickie marriages and divorces and the like (http://ptclub.com). This site is 'one of the leading "alternative" offshore providers in the world'. It offers you privacy, wealth and freedom and it really is astounding just what is available. There are maildrop and forwarding services in many countries providing a residential or street address, phone number with voice mail and fax reception. You can get a free legal South American passport, identity card, driving licence, bank account, maildrop, local residency - and you only need to visit the country one or twice a year (I wonder if you are eligible to be called up in the case of war?!). Do you want a tax-free car on Estonian plates? Or a Singapore Press Card? Or to have the title of Laird of John o' Groats? Want to moor your yacht in Grenada or buy a home there? No problem. Simply take out Grenadian nationality and get the passport. All very interesting - and if you are wondering what PT stands for then your guess is as good as mine!

\section{Photography and the Web}

No, I am not referring to all those pictures and galleries you can find on the Web! Instead, I am going to look at a couple of Web sites which can enhance your photos. Digital cameras are already integrally linked to the Internet, but the new tools on a photography Web site allow you to blend the fact of real live images with the fiction of fantasy worlds (http://www.cnn.com/2000/TECH/computing/12/13/holidays.in.toon.town.idg/index.html).

DotPhoto (http://www.dotphoto.com/) already allows you to store and manipulate photos on-line, but now that it is partnered with Kazoo3D (http://www.kazoo3D.com) you can add 3-D characters and images to your photos. Kazoo3D used advanced 3-D modelling and rendering and provides a free application called KazooStudio that uses the 3-D models to merge in with your own pictures. You can move, rotate and resize the 3-D models with the software as well as add lighting, shadow and paint effects. All good stuff - but people will have difficulties deciding just what is real and what is not.

But that is not all. If you do not own a digital camera, you can still improve the quality of your normal film by using a digital darkroom on the Web (http://www.cnn.com/2001/TECH/computing/01/08/digital.photography.ap/index.html). Several sites provide the service of converting traditional film into digital format at little or no charge. Post the film to one of these companies and you are notified when your images are posted on-line for you to crop, clean up, get rid of red-eye, etc. The pictures can then be sorted into on-line photo albums (which supposedly cannot be viewed by others) and emailed to others.

\section{Exploding Dictionary}

The Exploding Dictionary is really quite an interesting and useful site - especially if you want to while away a few minutes. The basic idea was to take a set of publicly available dictionaries, index them into an SQL database, and then cross-reference them to the limit. The result is a massive cross-referenced dictionary system - a kind of glorified Roget's thesaurus with hypertext, which permits the researcher or casual user to jump instantly to related or unknown material http://projects.ghostwheel.com/dictionary/.

Once you have entered a word to be looked up, the resulting information is provided twice. First it is displayed just as it would be in a normal dictionary (Websters Revised Unabridged 
1913 dictionary is used) with all the different meanings, and then below this it is displayed with each individual word hyperlinked. Thus you can click on any one of the hyperlinked words to either delve deeper into definitions, or follow completely new tracks.

Technojargon is a recent addition to the Exploding Dictionary which adds a large collection of recent technology words and phrases to the wealth of information already provided.

\section{Managing Web-enabled technologies}

The last item in this column is a press release I received about an innovative new book which examines Web-enabled technologies and their impact on organizations. There is an awful lot of hype and back patting in the blurb - but the book may be of interest to readers.

During the past two decades, advances in computer and telecommunication technologies have lead to the development of the Internet and its most popular application, the WorldWide Web (WWW). Many organizations have benefited from the technologies of the WWW, better known as Web-enabled technologies. By using these technologies, organizations have managed to reach customers and suppliers throughout the world in ways that would have been previously impossible. Web-enabled technologies allow firms of all sizes and types to find new strategic opportunities or to improve their strategic posture. At the same time, organizations are now using Web-enabled technologies in supporting internal organizational functions, particularly in areas of communications and information dissemination.

Like many other new technologies, Web-enabled technologies present organizations with many opportunities and significant challenges. Managing Web-enabled technologies in organizations: a global perspective, edited by Mehdi Khosrowpour, presents up-to-date research and practical findings related to Web-enabled technologies and their application. Additionally, this timely new book deals with managerial issues related to Web-enabled technologies in organizations. Edward Szewczak, a professor at Canisius College, remarked, 'This book does a thorough job of presenting key issues and perspectives on today's premier evolving technologies. A fascinating collection of articles.'

The coverage of Khosrowpour's new book ranges from the developmental issues of Webenabled technology applications to the issues of training and viability of these new technologies. Kenneth Kendall, a professor at Rutger's University, commented, 'This is a significant and innovative book in our field. It is a must-read book for anyone wanting to be versed in the most up-to-date issues surrounding international business on the Web. The international contributors address critical issues of Web-enabled organizations in an international economy in fresh and comprehensive ways. They cover such diverse areas such as Web development and design methodologies; training and managing e-commerce; and e-commerce in developing countries. This volume will set the standard for knowledge in Web-enabled technologies for years to come. 'Andrew Targowski of Western Michigan University echoed Professor Kendall's comments when he said, 'The book contributes to the emerging new world of business, which is driven by Web technologies. The reader can study the subject from critical issues through developmental solutions to education and training strategies.'

Web-enabled technologies are changing the way businesses conduct business across the globe. Khosrowpour's new book addresses the essential parts of understanding this new technology and its implications. Professor Kendall remarked, 'A timely book that precisely targets two areas of critical concern for today's businesses: strategically managing the Web and how organizations can cope with Web-enabled technologies globally. It should be required reading for all business students and scholars who need to be well versed in the most critical and topical issues of our day. This book will quickly establish a standard that 
will dominate the field. I highly recommend it.'

Edward Szewczak elaborated, 'Relevant to researchers and practitioners alike, this collection captures the state-of-the-art in managing Web-enabled technologies.' This book is more than a textbook, technical readings, or a practical guide; the contributing authors cover all aspects of Web-enabled technologies. Professor Kendall explained further, 'A new book of epic proportions. The contributing authors are to be congratulated on creating a book of essential readings for any student, professor, or businessperson who wants to quickly and completely understand the strategic use of Web-enabled technologies as they relate to organizations conducting business on the Web. I heartily recommend it to all those who want to be well read in the most significant e-commerce management, development and design topics of our day. It is a ground breaking book that will easily become the new standard on effectively using Web-enabled technologies.' Authors from around the globe describe their experiences in using Web-enabled technologies and the influence these technologies are having globally. Professor Szewczak explained, 'This book does exactly what its title says - it presents a global perspective on managing global technology. It should appeal to a wise and intelligent audience.' Managing Web-enabled technologies in organizations: a global perspective presents a compendium of useful material. It is a must read for anyone in business or academia who seeks to understand the influence and applications of Web-enabled technologies.

The Editor, Mehdi Khosrowpour, is currently an Associate Professor of Information Systems at Penn State Harrisburg University. He is the editor in charge of the Information Resource Management Journal and Information Management. In addition, he serves on the editorial review boards of six other international information systems journals. Dr Khosrowpour is the author/editor of 12 books and more than 30 journal articles published in various scholarly and professional journals such as the Journal of Information Systems Management, Business Review, Journal of Computer Information Systems and Journal of Education Technology Systems. His recent book Managing Web-enabled technologies in organizations: a global perspective is available from Idea Group Publishing, Hershey, PA (261 pages, Copyright 2000, ISBN: 1-878289-72-1, http://www.idea-group.com

\section{David Raitt}

\section{Disclaimer}

Articles published in SAJIM are the opinions of the authors and do not necessarily reflect the opinion of the Editor, Board, Publisher, Webmaster or the Rand Afrikaans University. The user hereby waives any claim he/she/they may have or acquire against the publisher, its suppliers, licensees and sub licensees and indemnifies all said persons from any claims, lawsuits, proceedings, costs, special, incidental, consequential or indirect damages, including damages for loss of profits, loss of business or downtime arising out of or relating to the user's use of the Website.

ISSN 1560-683X

Published by InterWord Communications for the Centre for Research in Web-based Applications, Rand Afrikaans University 